\title{
Root characteristics of Alhagi sparsifolia seedlings in response to water supplement in an arid region, northwestern China
}

\author{
DongWei GUI ${ }^{1,2,3}$, FanJiang ZENG ${ }^{1,2,3^{*}}$, Zhen LIU $^{2}$, Bo ZHANG ${ }^{1,2,3}$ \\ ${ }^{1}$ State Key Laboratory of Desert and Oasis Ecology, Xinjiang Institute of Ecology and Geography, Chinese Academy of Sci- \\ ences, Urumqi 830011, China; \\ ${ }^{2}$ Cele National Station of Observation \& Research for Desert-Grassland Ecosystem in Xinjiang, Cele 848300, China; \\ ${ }^{3}$ Key Laboratory of Biogeography and Bioresource in Arid Land, Xinjiang Institute of Ecology and Geography, Chinese Acad- \\ emy of Sciences, Urumqi 830011, China
}

\begin{abstract}
The effect of variation in water supply on woody seedling growth in arid environments remain poorly known. The subshrub Alhagi sparsifolia Shap. (Leguminosae), distributed in the southern fringe of the Taklimakan Desert, Xinjiang, northwestern China, has evolved deep roots and is exclusively dependent on groundwater, and performs a crucial role for the local ecological safety. In the Cele oasis, we studied the responses of $A$. sparsifolia seedling roots to water supplement at 10 and 14 weeks under three irrigation treatments (none water supply of 0 $\mathrm{m}^{3} / \mathrm{m}^{2}(\mathrm{NW})$, middle water supply of $0.1 \mathrm{~m}^{3} / \mathrm{m}^{2}(\mathrm{MW})$, and high water supply of $0.2 \mathrm{~m}^{3} / \mathrm{m}^{2}(\mathrm{HW})$ ). The results showed that the variations of soil water content (SWC) significantly influenced the root growth of $A$. sparsifolia seedlings. The leaf area, basal diameter and crown diameter were significantly higher in the HW treatment than in the other treatments. The biomass, root surface area (RSA), root depth and relative growth rate (RGR) of $A$. sparsifolia roots were all significantly higher in the NW treatment than in the HW and MW treatments at 10 weeks. However, these root parameters were significantly lower in the NW treatment than in the other treatments at 14 weeks. When SWC continued to decline as the experiment went on (until less than $8 \%$ gravimetric SWC), the seedlings still showed drought tolerance through morphological and physiological responses, but root growth suffered serious water stress compared to better water supply treatments. According to our study, keeping a minimum gravimetric SWC of $8 \%$ might be important for the growth and establishment of $A$. sparsifolia during the early growth stage. These results will not only enrich our knowledge of the responses of woody seedlings to various water availabilities, but also provide a new insight to successfully establish and manage $A$. sparsifolia in arid environments, further supporting the sustainable development of oases.
\end{abstract}

Keywords: arid environment; Alhagi sparsifolia; roots; irrigation treatments; oasis

Citation: DongWei GUI, FanJiang ZENG, Zhen LIU, Bo ZHANG. 2013. Root characteristics of Alhagi sparsifolia seedlings in response to water supplement in an arid region, northwestern China. Journal of Arid Land, 5(4): 542-551. doi: 10.1007/s40333-013-0186-7

Water stress is a key factor limiting plant survival and growth, species composition, and community structure in arid areas, and consequently negatively impacts vegetation restoration (Jackson et al., 1996; Schenk and Jackson, 2005; Bruelheide et al., 2010; Li et al., 2010; Vonlanthen et al., 2011). Understanding of seedling responses to changes in water availability is essential for the vegetation restoration programs in arid regions. Physiological and morphological variations occur in plants in response to various water availabilities. The significance of water stress in plant physiology and growth has been recognized by many

\footnotetext{
*Corresponding author: FanJiang ZENG (E-mail: zengfj@ms.xjb.ac.cn) Received 2012-11-12; revised 2013-01-20; accepted 2013-02-20

(C) Xinjiang Institute of Ecology and Geography, Chinese Academy of Sciences, Science Press and Springer-Verlag Berlin Heidelberg 2013
} 
researchers in the last decades (Anyia and Herzog, 2004; Dias et al., 2007; Li et al., 2008; Xu et al., 2010; Mao et al., 2012). However, there has been less attention to water stress during seedling development process (Li et al., 2008; Padilla et al., 2009; Xu et al., 2010). Yet, increasing the probability of seedling establishment and vigorous growth under water-stressed conditions is one of the first steps in successful revegetation of arid habitats.

Perennial shrub species growing in deserts rely on access to water in deep soil layers (Sala and Lauenroth, 1982; Padilla and Pugnaire, 2007). Desert shrubs must have deep-reaching roots to tap the soil water at great depths; thus making them record holders of maximum rooting depth compared to plants from all other ecosystems (Seyfried et al., 2005; Vonlanthen et al., 2010; Zhang et al., 2012). Similarly, for successful establishment, desert phreatophytes require extremely fast root growth to reach the deeper groundwater table or to follow a declining groundwater table (Vonlanthen et al., 2011). The root system plays a key role in overcoming water stress and establishing plants in desert areas. Early root development in response to limited water availability has become a strategy to ensure seedling recruitment (Li et al., 2008; Xu et al., 2010; Vonlanthen et al., 2011). It is often speculated that drought limits seedling growth and development (Nicotra et al., 2002; Ryster, 2006; Padilla and Pugnaire, 2007); however, drought tolerance of woody seedlings has not been investigated in detail. In addition, little is known about the effects of variation in water supply on root and shoot growth of shrub seedlings in extreme arid environments.

Alhagi sparsifolia Shap. (Leguminosae) is a spiny, perennial subshrub whose shoots die in winter and re-sprout again in spring. Seeds reach maturity by the end of September or October and are dispersed by mammals. A. sparsifolia grows in salinized and arid regions in the native ranges of northwestern China, Central Asia, India, and Middle and Near East; while for North America the plant is an invader (Vonlanthen et al., 2011). As a phreatophyte species, A. sparsifolia has evolved deep roots and is exclusively dependent on groundwater in desert environments (Gries et al., 2005; Thomas et al., 2006, 2008; Bruelheide et al.,
2010). The adaptation of deeper roots reaching the groundwater is crucial for $A$. sparsifolia distributed in the foreland of the oases at the southern fringe of the Taklimakan Desert, Xinjiang, northwestern China (Zeng et al., 2006; Gui et al., 2010). Moreover, $A$. sparsifolia is an important fodder for local animals because of its high protein content, and plays an important role in the development of local livestock husbandry. Researchers have estimated that the $A$. sparsifolia in Xinjiang covers about $1.73 \times 10^{6} \mathrm{hm}^{2}$ and is mainly concentrated at the southern fringe of the Taklimakan Desert (Zeng et al., 2006). In addition, as a dominant species, A. sparsifolia, along with other perennial indigenous species, such as Tamarix ramosissima Ledeb. (Tamaricaceae) and Karelinia caspica (Pall.) Less. (Compositae), constitutes a shelter belt against the strong winds which constantly transport sand from the desert into the oases (Siebert et al., 2004; Gui et al., 2010; Vonlanthen et al., 2011). Therefore, $A$. sparsifolia is often seen as a part of the oasis agricultural system (Thomas et al., 2000; Siebert et al., 2004; Zeng et al., 2006; Vonlanthen et al., 2010).

Previous studies showed that A. sparsifolia can be established through vegetative reproduction via root suckers and seedling recruitment via seeds (Vonlanthen et al., 2010; Zhang et al., 2012). Regardless of propagation method, A. sparsifolia roots must grow extremely fast to reach or follow the receding groundwater to guarantee successful establishment (Padilla et al., 2007). Liu et al. (2009), by using a concrete pit experiment, found that $A$. sparsifolia roots can reach $2.5 \mathrm{~m}$ in a single growing season. In some river plains with groundwater depths of about $6.5 \mathrm{~m}$, experiments using PVC tubes in the field and glasshouse indicated that such depths could be reached by the roots of juvenile $A$. sparsifolia within 5-6 months (Vonlanthen et al., 2011). Generally, in some regions with deeper groundwater, A. sparsifolia may rely on flooding for successful seedling establishment. However, in the research on the effects of sporadic flooding events on A. sparsifolia, Zeng et al. (2006) clearly illustrated that flooding did not influence $A$. sparsifolia due to the absence of fine roots in the topsoil layer, and also had no significant influence on ramet production. Guo et al. (2008) further simulated the effects of repetitive 
repetitive flooding on A. sparsifolia, and found a positive effect on seedlings generated by root suckers but little influence on seed propagation. Although these researches enriched our knowledge about the ecological adaption of $A$. sparsifolia in hyperarid environments, questions remain and are to be further investigated. How do seedlings respond to different water supply conditions, and how could effective establishment be accomplished with deeper groundwater tables?

In recent decades, a large area of $A$. sparsifolia at the southern fringe of the Taklimakan Desert has been seriously damaged due to oasis expansion under the pressure of economic development and population growth (Gui et al., 2009; Vonlanthen et al., 2010, 2011). Additionally, the increase in water use for agriculture has contributed to the fall of groundwater depth, with adverse effects on seedling survival and growth (Ma et al., 2007; Gui et al., 2009; Vonlanthen et al., 2011). Consequently, large areas of oasis foreland were deprived of vegetation, leading to not only negative impacts on the development of livestock husbandry but also sand encroachment into agricultural land. Therefore, re-establishment and restoration of plant populations in these regions is crucial. Due to the deterioration of $A$. sparsifolia and decline of groundwater table in the oasis-desert ecotone at the southern fringe of the Taklimakan Desert, establishment by seeds seems to be more important, and the early growth of $A$. sparsifolia under water-stressed conditions should be evaluated. Thus, this study mainly analyzed the response of $A$. sparsifolia seedlings to different irrigation treatments in oasis foreland with deep groundwater table. The objectives were to: (1) study the influences of different irrigation treatments on the growth of $A$. sparsifolia seedlings; (2) investigate the effects of water stress on the growth of A. sparsifolia seedling roots; and (3) provide a theoretical basis for the restoration of $A$. sparsifolia population in such a hyperarid environment.

\section{Materials and methods}

\subsection{Study area}

The study area is located in the foreland of Cele oasis at the central part of the southern fringe of the Takli- makan Desert, Xinjiang Uyghur autonomous region, northwestern China. The area is characterized by an arid climate, with an average annual precipitation of 35 $\mathrm{mm}$ and evaporation of $2,595 \mathrm{~mm}$. The annual mean temperature is $11.9^{\circ} \mathrm{C}$. The study area is perennially windy, with a predominant wind direction of north-west (Gui et al., 2010). The groundwater depth in this oasis-desert ecotone changes from 2 to $15 \mathrm{~m}$. Soil texture remains homogenous with increasing depth. The silt content is higher than $88 \%$ and the maximum sand content is about $8 \%$ (Thomas et al., 2000).

\subsection{Experimental design}

The experiments were conducted at the Cele National Station of Observation \& Research for Desert-Grassland Ecosystem in Xinjiang, northwestern China $\left(37^{\circ} 00^{\prime} 56^{\prime \prime} \mathrm{N}, 80^{\circ} 43^{\prime} 45^{\prime \prime} \mathrm{E}\right)$. The groundwater depth was $14 \mathrm{~m}$. Calculations of flood in this oasis-desert ecotone showed that historically the amount of naturally occurring flood was around $0.2 \mathrm{~m}^{3} / \mathrm{m}^{2}$ (Guo et al., 2008). In this study, three irrigation treatments of seedling response to water supplement were designed, i.e. none water supply of $0 \mathrm{~m}^{3} / \mathrm{m}^{2}$ (NW), middle water supply of $0.1 \mathrm{~m}^{3} / \mathrm{m}^{2}$ (MW), and high water supply of $0.2 \mathrm{~m}^{3} / \mathrm{m}^{2}$ (HW). Three replicate experimental plots for each irrigation treatment were set, and every plot has an area of $4 \mathrm{~m} \times 4 \mathrm{~m}$. Nine plots with a total area of $144 \mathrm{~m}^{2}(12 \mathrm{~m} \times 12 \mathrm{~m})$ were then established for the three irrigation treatments. Plastic sheets were buried at a depth of $1 \mathrm{~m}$ in every neighboring plot to prevent seepage.

Seeds of $A$. sparsifolia were collected in the autumn of 2009 , and $5-10$ seeds were sown in a $3-\mathrm{cm}$ deep hole at an interval of $80 \mathrm{~cm}$ (total 9 holes in each plot) on 14 May 2010. For guaranteeing seed germination, an irrigation at a height of $15 \mathrm{~cm}$ prior to sowing for providing a moist soil environment to a $30-\mathrm{cm}$ depth in each plot was conducted. In addition, seeds were scarified for 20 mins in $98 \%$ sulfuric acid (Vonlanthen et al., 2010). When seedlings emerged, a little water was provided in every hole to guarantee seedling survival until 5 June. One month after sowing (i.e. 14 June), seedlings were thinned to one per hole, and mean rooting depths of the redundant seedlings were recorded. During this period, management was uni- 
form among all the experimental plots.

Irrigation treatments were conducted beginning from 15 June. At 10 (23 August) and 14 (23 September) weeks after 15 June, seedlings were harvested respectively at the two different developmental stages to investigate growth traits (The 10 weeks and 14 weeks hereinafter refer to the time length after irrigation). The six seedling replicates (two seedlings per plot) were used to analyze growth traits under each irrigation treatment. The root tracking and sieving methods were adopted during excavation so that all roots were removed from each layer. The root depth, total dry biomass, root:shoot ratio (R:S), specific leaf area (SLA, $\mathrm{cm}^{2} / \mathrm{g}$ ), root surface area (RSA, $\mathrm{mm}^{2}$ ), and relative growth rate $(\mathrm{RGR}, \mathrm{cm} /(\mathrm{cm} \cdot \mathrm{d}))$ of rooting in layers were then calculated. RGR for the first investigation was based on the mean rooting depth on 14 June, and for the second investigation it was based on the mean rooting depth at the first time of harvest. SLA was analyzed by Win-Folia (Regent Instruments Inc., Quebec, Canada) through scanned fresh leaf per seedling. RSA was calculated by the following formula: $\mathrm{RSA}=3.14 \times \mathrm{D}$ (diameter, measured by Vernier caliper) $\times \mathrm{L}$ (root length) (Waisel et al., 1996).

In each plot, soil water content (SWC) was measured four times to a depth of $200 \mathrm{~cm}$ at $20-\mathrm{cm}$ intervals. The four SWC sampling times were $1 \mathrm{~d}$ before irrigation (14 June), $2 \mathrm{~d}$ after irrigation (17 June), the first harvesting time (23 August), and the second harvesting time (23 September), respectively. Soil samples collected by a soil auger and an aluminum box were oven-dried at $105^{\circ} \mathrm{C}$ to a constant weight, and then gravimetric SWC was measured. In addition, seedling roots and shoots were oven-dried for $48 \mathrm{~h}$ at $70^{\circ} \mathrm{C}$ for biomass determination.

\subsection{Data analysis}

One-way analyses of variance (ANOVA) were performed to determine the effects of different irrigation treatments on the measured seedling variables. If the main effects were significant $(P<0.05)$, a post-hoc separation of means was done by univariate least significant difference (LSD) test. ANOVA and LSD analyses were conducted using SPSS 16.0 software; and Excel and Origin software were used to plot figures.

\section{Results and discussion}

\subsection{Variation in SWC within 200-cm depth under different irrigation treatments}

In the study area, the soil field capacity (FC) was $12 \%-18 \%$ (gravimetric SWC) (Bruelheide et al., 2010). The initial values of SWC were around $8 \%$ in the $200-\mathrm{cm}$ depth (Fig. 1a). Following the irrigation treatments, the water mainly infiltrated to 90 and 180 $\mathrm{cm}$ deep for the MW and HW treatments, respectively, and the SWC decreased from FC to around $8 \%$ (Fig. $1 b)$. The SWC variability indicated that although water leached after the irrigation, the water holding capacity could maintain the SWC at an $8 \%$ level based on the soil texture (Figs. 1a and b). However, due to plant water uptake, the SWC decreased further to less than $8 \%$ as the experiment continued. At 10 weeks, SWC within 100-cm depth decreased dramatically to $<8 \%$ for the NW and MW treatments, while the SWC was $<8 \%$ within the depth of $80-140 \mathrm{~cm}$ for the HW treatment (Fig. 1c). At 14 weeks, the SWC further declined, and was $<8 \%$ within 200 -cm depth for each irrigation treatment (Fig. 1d). In addition, compared with the NW treatment, SWC in the HW and MW treatments within the depth of 100-200 cm increased significantly as the experiment continued (Figs. 1c and d).

\subsection{Variation in seedling growth under different irrigation treatments}

Seedling growth characteristics were directly influenced by different irrigation treatments. When seedlings were 10 weeks old, the stem biomass, leaf biomass, leaf area, basal diameter and crown diameter were all significantly higher for the HW treatment than for the other treatments (Table 1), suggesting that the HW treatment benefited $A$. sparsifolia seedling growth, which was in agreement with previous experiments with different water supply treatments in leguminous shrub Bauhinia faberi var. microphylla (Li et al., 2008). However, no significant differences were observed between the MW and NW treatments (Table 1), indicating that $A$. sparsifolia seedling growth was not significantly affected by lower irrigation treatments. Moreover, there were significant differences in stem biomass, leaf biomass, leaf area, and basal and 


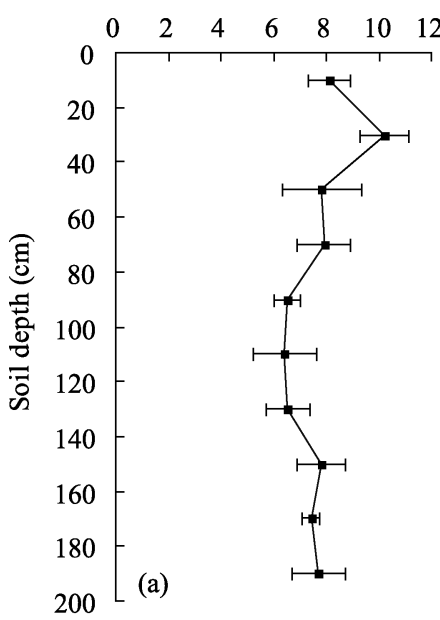

14 June

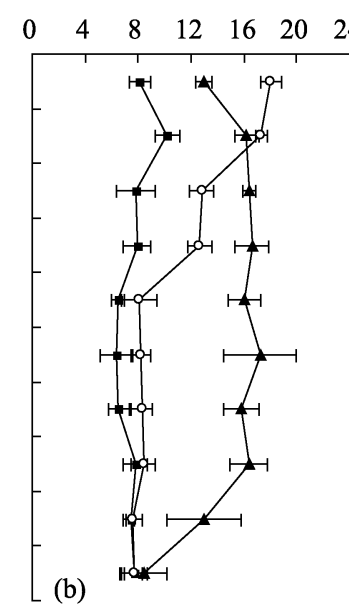

17 June

Soil water content (\%)

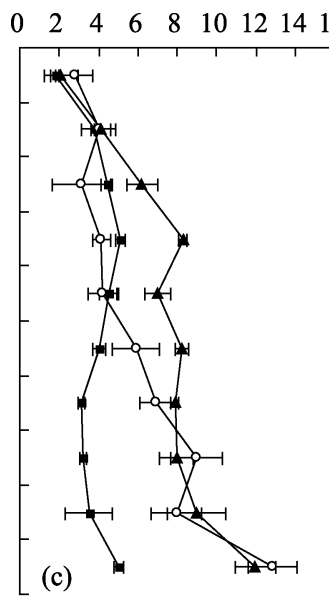

23 August

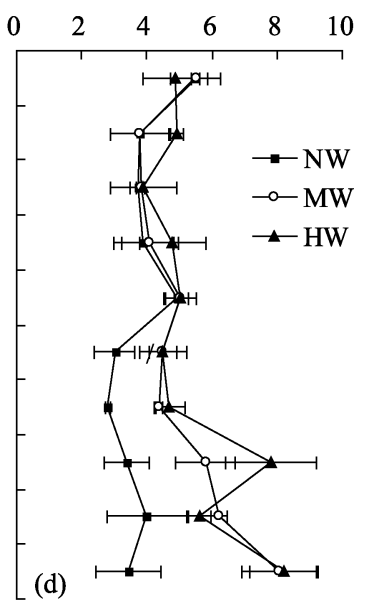

23 September

Fig. 1 Variations of soil water contents within 200-cm depth under different irrigation treatments at the four sampling times

Table 1 Variations of growth indices for Alhagi sparsifolia seedlings at 10 weeks under different irrigation treatments

\begin{tabular}{lllllll}
\hline $\begin{array}{l}\text { Irrigation treatment } \\
\left(\mathrm{m}^{3} / \mathrm{m}^{2}\right)\end{array}$ & $\begin{array}{l}\text { Stem biomass } \\
(\mathrm{g})\end{array}$ & $\begin{array}{l}\text { Leaf biomass } \\
(\mathrm{g})\end{array}$ & $\begin{array}{l}\text { Leaf area } \\
\left(\mathrm{mm}^{2}\right)\end{array}$ & $\begin{array}{l}\text { Plant height } \\
(\mathrm{cm})\end{array}$ & $\begin{array}{l}\text { Basal diameter } \\
(\mathrm{mm})\end{array}$ & $\begin{array}{l}\text { Crown diameter } \\
(\mathrm{cm})\end{array}$ \\
\hline $\mathrm{NW}$ & $0.38 \pm 0.04 \mathrm{~b}$ & $0.44 \pm 0.10 \mathrm{~b}$ & $4963.20 \pm 1071.66 \mathrm{~b}$ & $11.60 \pm 1.29 \mathrm{a}$ & $2.24 \pm 0.06 \mathrm{~b}$ & $314.00 \pm 40.54 \mathrm{~b}$ \\
$\mathrm{MW}$ & $0.55 \pm 0.09 \mathrm{~b}$ & $0.68 \pm 0.13 \mathrm{~b}$ & $8140.18 \pm 1521.52 \mathrm{~b}$ & $16.00 \pm 4.08 \mathrm{a}$ & $2.61 \pm 0.14 \mathrm{ab}$ & $513.50 \pm 38.29 \mathrm{ab}$ \\
$\mathrm{HW}$ & $1.24 \pm 0.09 \mathrm{a}$ & $1.08 \pm 0.07 \mathrm{a}$ & $13364.52 \pm 1163.21 \mathrm{a}$ & $15.40 \pm 2.36 \mathrm{a}$ & $2.72 \pm 0.17 \mathrm{a}$ & $694.60 \pm 114.33 \mathrm{a}$ \\
\hline
\end{tabular}

Note: NW, none water supply of $0 \mathrm{~m}^{3} / \mathrm{m}^{2}$; MW, middle water supply of $0.1 \mathrm{~m}^{3} / \mathrm{m}^{2} ; \mathrm{HW}$, high water supply of $0.2 \mathrm{~m}^{3} / \mathrm{m}^{2}$. Different lowercase letters represent significant differences among irrigation treatments $(P<0.05)$.

crown diameters between the HW and NW treatments. The average heights of seedlings were $11.6-16.0 \mathrm{~cm}$, with no significant differences among the three irrigation treatments (Table 1). The variations in seedling growth at 14 weeks were similar to those at 10 weeks. These growth variables under NW and MW treatments were almost significant at the lowest level, further indicating that species should minimize investment in growth so as to more efficiently utilize the limiting water resources in arid environments (Ryster, 2006; Li et al., 2008; Vonlanthen et al., 2010).

\subsection{Variation in seedling root traits under differ- ent irrigation treatments}

\subsubsection{Root depth and RGR}

At 10 weeks, the average root depth of $A$. sparsifolia seedlings for the HW treatment was $50 \mathrm{~cm}$, which was not significantly different from that for the MW treatment $(47 \mathrm{~cm})$; however, the root depths for both HW and MW treatments were all significantly less than that for the NW treatment $(60 \mathrm{~cm}$; Fig. 2). The mean RGR at 10 weeks with increasing irrigation treatments were $0.86,0.67$ and $0.71 \mathrm{~cm} /(\mathrm{cm} \cdot \mathrm{d})$, respectively. It showed that lower SWC stimulated fast root growth, which is consistent with the results from Liu et al. (2009) and Zeng et al. (2009). However, at 14 weeks, the average root depth for the HW treatment increased to $100 \mathrm{~cm}$ and was significantly higher than that for the MW and NW treatments, with 75 and $80 \mathrm{~cm}$, respectively (Fig. 2). The mean RGR at 14 weeks increased with increasing levels of irrigation, measuring 0.71, 0.90 and $1.61 \mathrm{~cm} /(\mathrm{cm} \cdot \mathrm{d})$, respectively. The HW treatment at 14 weeks had the greatest root depth and RGR, showing that continuously lower SWC had negative effects on root growth. These results indicated that although the drier treatment stimulated root growth throughout the initial seedling stage, better water supply is still important for root growth on the whole. For instance, Vonlanthen et al., (2010) reported that in PVC tube experiments $(6.5-\mathrm{m}$ groundwater depth) with better 
water and fertilizer supply, A. sparsifolia seedling root depth was $1.7 \mathrm{~m}$ with $4.1 \mathrm{~cm} /(\mathrm{cm} \cdot \mathrm{d}) \mathrm{RGR}$ in four months. This value was significantly higher than found in our study. Although the root depth and RGR of $A$. sparsifolia seedling were lower in our study area than in better soil environments, our research was done in-situ and reflected the native environment and natural root growth. Furthermore, the RGR of $A$. sparsifolia in our research was higher than that for many other plants (Vonlanthen et al., 2010).

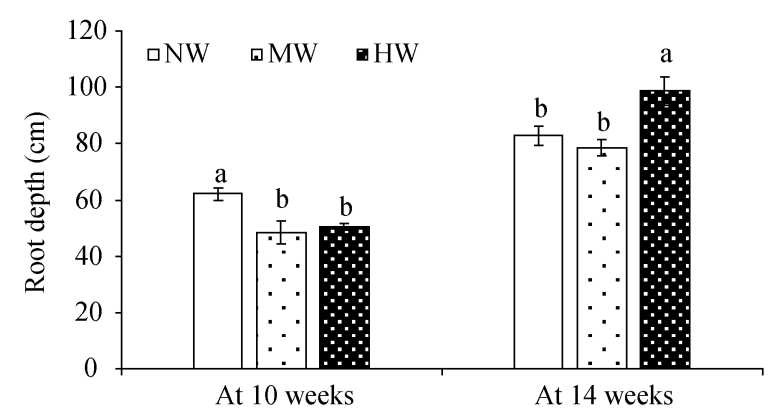

Fig. 2 Root depths of $A$. sparsifolia seedling at 10 weeks and 14 weeks under different irrigation treatments

These variations in root depths and RGR indicated that plant responses to water deficits are dynamic and change (Hodge, 2004; Maestre and Reynolds, 2007; Padilla et al., 2007). In long-term observations at Cele Station, the root growth of $A$. sparsifolia seedlings decreased under drought stress with $\mathrm{SWC}<8 \%$ (unpublished data). The bulk density of soil in the study area was around $1.2 \mathrm{~g} / \mathrm{cm}^{3}$, and additional soil texture data and pedotransfer functions were used to compute the soil matric potential (Cornelis et al., 2001) — given that the soil matric potential at $8 \%$ gravimetric SWC (10\% volumetric SWC) was around $-0.6 \mathrm{MPa}$. The soil matric potential decreased significantly for gravimetric $\mathrm{SWC}<8 \%$ (10\% volumetric SWC). For example, Vonlanthen et al. (2010) recorded that the water potentials of $A$. sparsifolia seedlings were between -1.4 and $-0.6 \mathrm{MPa}$. Therefore, the soil matric potential at SWC of $8 \%$ was higher than the plant water potential and thus beneficial for water uptake. However, at $\mathrm{SWC}<8 \%$, the water uptake capacity would be affected by the lower soil matric potential. Thus, considering the relative homogeneity in soil texture (Thomas et al., 2000), the $8 \%$ gravimetric SWC might be a be a threshold value for the growth and establishment of $A$. sparsifolia seedlings.

Our research further indicated that changes in root growth occurred at around $8 \%$ gravimetric SWC. Up to 10 weeks, the SWC within the root depth range for the NW treatment fell from $8 \%$ to $<8 \%$, and this change in SWC stimulated fast root growth to reach deeper groundwater, and then produced the highest RGR of $0.86 \mathrm{~cm} /(\mathrm{cm} \cdot \mathrm{d})$; in contrast, the HW and MW treatments, which had higher SWC within the root depth range, had lower RGR. However, during 10-14 weeks, the SWC within the depth of 60-100 cm range for the HW treatment decreased dramatically from nearly $8 \%$ to $<8 \%$, and also showed the highest RGR of $1.61 \mathrm{~cm} /(\mathrm{cm} \cdot \mathrm{d})$. Within the depth of $60-100 \mathrm{~cm}$, the SWC was always $<8 \%$ for the NW treatment, and the drought stress caused the RGR to dramatically decrease to $0.71 \mathrm{~cm} /(\mathrm{cm} \cdot \mathrm{d})$. As a result, root length was lowest in the NW treatment. These results indicated that although $A$. sparsifolia has higher drought tolerance (Vonlanthen et al., 2010), the process of SWC decreasing to $<8 \%$ greatly affected root growth. During the early growth stage, the moisture stress may promote root growth, but in a longer term it seriously decreased root length and affected the establishment of $A$. sparsifolia seedlings.

\subsubsection{Root biomass and R:S}

Root biomass was mainly concentrated at the $0-40 \mathrm{~cm}$ soil depth ( $>80 \%$ of the total root biomass) with larger root diameters, and it decreased dramatically with increasing soil depths (Fig. 3). Similarly, with the variation of root depth, total root biomass was significantly higher in the NW treatment than in the other treatments at 10 weeks, and significantly higher in the HW treatment than in the other treatments at 14 weeks. There were no significant differences in root biomass among the different irrigation treatments within the 0-40 cm soil depth at 10 weeks and 14 weeks, and significant differences were mainly concentrated at greater soil depths, i.e. $40-60 \mathrm{~cm}$ at 10 weeks and $40-100 \mathrm{~cm}$ at 14 weeks. This indicated that the root depth directly influenced variations in root biomass.

The R:S values for the NW treatment at 10 weeks and 14 weeks were 0.2 and 1.3 , respectively, and were 


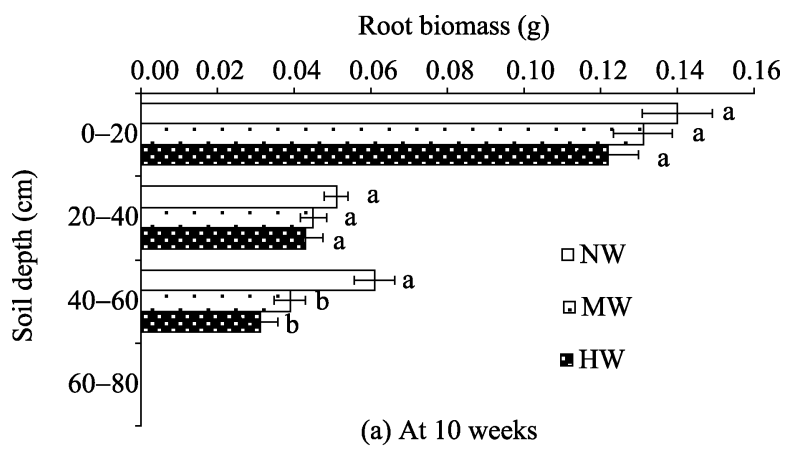

(a) At 10 weeks

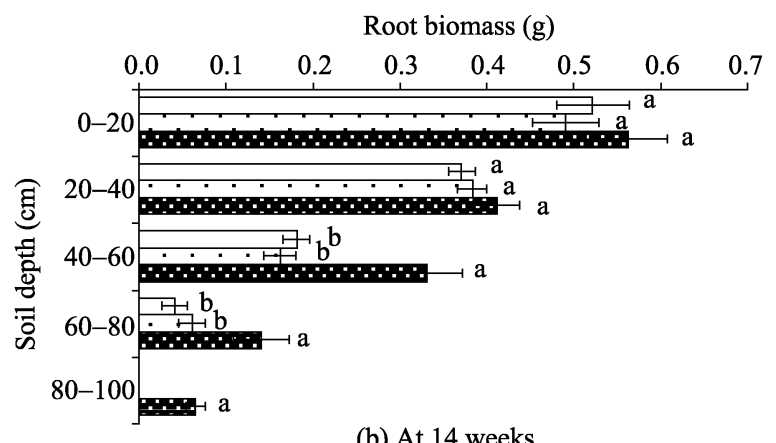

(b) At 14 weeks

Fig. 3 Root biomass of $A$. sparsifolia with varying soil depths under different irrigation treatments at 10 weeks (a) and 14 weeks (b)

significantly higher than for the MW and HW treatments. At 10 weeks, the aboveground growth indices for A. sparsifolia seedlings were significantly lower in the NW treatment than in the other treatments; however, to better acquire groundwater, plants in the NW treatment developed longer roots and higher root biomass, thus R:S was significantly higher in this irrigation treatment than in the other treatments. At 14 weeks, the root biomass was significantly higher in the HW treatment than in the other treatments; however, as aboveground biomass was also significantly higher in the HW treatment than in the NW treatment, $\mathrm{R}: \mathrm{S}$ was also highest in the NW treatment. Numerous studies have shown that water stress changes total dry mass and its components, and allocates biomass to root systems, resulting in higher R:S in water-stressed seedlings (Jackson et al., 1996; Seyfried et al., 2005; Arredondo and Johnson, 2009). Zeng et al. (2012) believed that the plasticity of root morphology and higher R:S were two important strategies for A. sparsifolia to capture water and adapt to a hyperarid environment. The highest R:S in the NW treatment in the present study confirmed this result. Under higher soil moisture conditions, plants may have less demand to develop roots and so allocate more biomass to shoot growth, thus resulting in a lower R:S (Li et al., 2008; Arredondo and Johnson, 2009; Padilla et al., 2009).

Vonlanthen et al. (2010) found that there was no effect of irrigation on $\mathrm{R}: \mathrm{S}$ of $A$. sparsifolia seedlings in greenhouse experiments, and then concluded that the difference in SWC between irrigation and non-irrigation treatments was not enough to invoke different responses in plants. However, in the present study, we found that there were significant differences in $\mathrm{R}: \mathrm{S}$ among the three irrigation treatments at 10 and 14 weeks, indicating that different water supply treatments had invoked different responses in A. sparsifolia seedlings. Results showed that only when the variations in SWC caused water stress to A. sparsifolia, did root biomass and R:S change. According to our analysis, the gravimetric SWC of $8 \%$ may be a threshold value for these effects.

\subsubsection{RSA and SLA}

The total RSA at 10 weeks was significantly higher in the NW treatment than in the HW and MW treatments, while at 14 weeks the total RSA in the HW treatment was the highest (Fig. 4). In addition, there were no significant differences in SLA among different irrigation treatments at either 10 or 14 weeks. However, SLA decreased obviously as the experiment continued, with it being lower at 14 weeks than at 10 weeks for all irrigation treatments (Fig. 5).

Significant differences in root biomass among the irrigation treatments at the two seedling ages (10 and 14 weeks) mainly existed in deeper soil layers where absorbing roots were mainly distributed (Fig. 3). Likewise, there were also significant differences in RSA among the irrigation treatments at 10 and 14 weeks in deeper soil layers (Fig. 4). These indicated that seedling roots mainly increased the biomass and RSA of absorbing roots to increase their resource uptake capacity. The observed changes in growth, biomass production and $\mathrm{R}: \mathrm{S}$ of $A$. sparsifolia for different irrigation treatments were consistent with other studies of tree seedlings (Yin et al., 2004), shrubs (Villagra and Cavagnaro, 2006), and herbs (Li et al., 2008; Xu et al., 2010).

SLA showed no differences among the irrigation treatments at the sampling times (i.e. 10 and 14 
weeks), possibly because SLA was already low in the drought treatments. Nevertheless, SLA showed a decreasing trend with time increased, as found in other species expressing reduced leaf area as a morphological adaptation for reducing water loss (Buchanan-Wollaston, 1997; Maggio et al., 2005). Prolonged drought can limit the growth and biomass production of plants, and can even cause plants' death. The present study indicated that although there was no plant mortality during the experiment, the $A$. sparsifolia seedlings were vulnerable to severe drought conditions because of lower SWC in deeper soil layers.

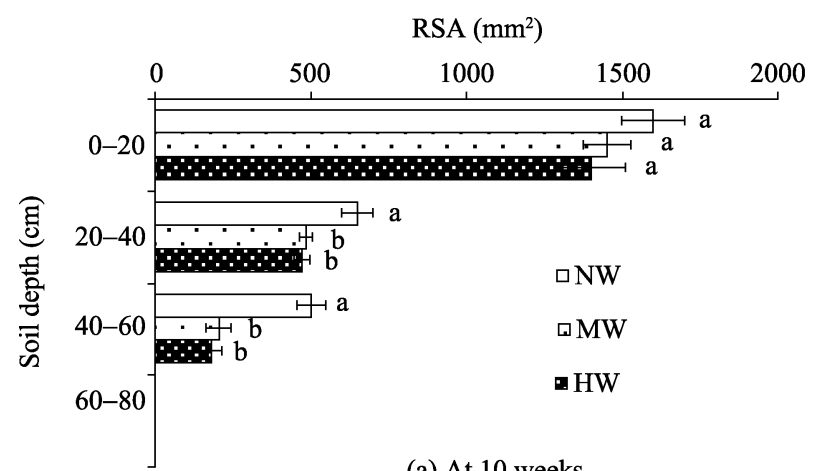

(a) At 10 weeks

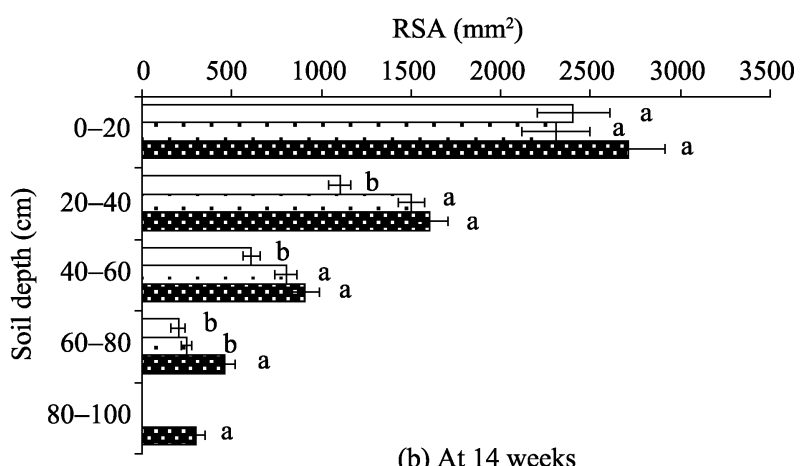

(b) At 14 weeks

Fig. 4 Root surface area (RSA) of $A$. sparsifolia at different soil depths and for different irrigation treatments at 10 weeks (a) and 14 weeks (b)

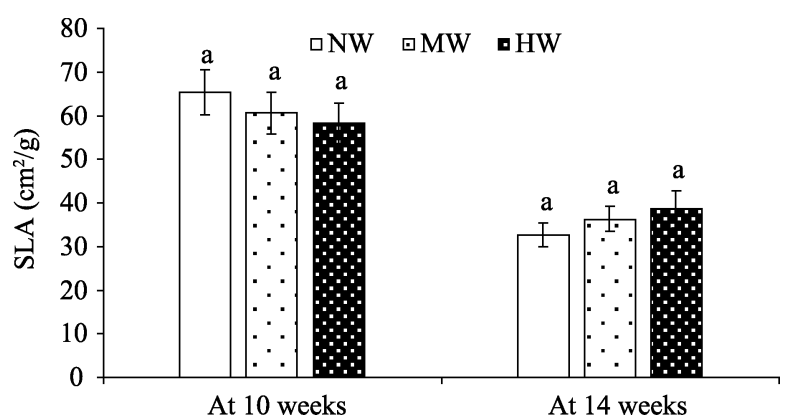

Fig. 5 Specific leaf area (SLA) of $A$. sparsifolia for different irrigation treatments at 10 weeks and 14 weeks

\section{Conclusions}

Our research showed that different irrigation treatments affected $A$. sparsifolia seedling growth. However, compared to the aboveground growth traits, there were generally more pronounced variations in root growth and morphology traits, including RGR, root biomass allocation and R:S. Thus, A. sparsifolia adjusted its root structure to adapt to the variations in SWC, and showed high drought tolerance even when SWC was very low. It is an important strategy for $A$. sparsifolia to capture water and survive in such a hyperarid environment. The SWC undoubtedly plays a key role in the root growth and successful establishment of $A$. sparsifolia. A minimum gravimetric SWC of $8 \%$ was important, as the soil matric potential was higher than the plant water potential.

This study provides useful information for the better management and establishment of $A$. sparsifolia. Firstly, some protective measures, especially better water supply, are needed to guarantee seedling survival during the stage of seed germination. A hyperarid environment can cause the SWC in the $40-\mathrm{cm}$ topsoil to decline dramatically after a flooding event, and result in low soil matric potential ( $8 \%$ gravimetric SWC) that severely affects seed germination and establishment.

Secondly, although there was no plant mortality in the three irrigation treatments and considering that the growth indices in the NW treatment significantly decreased with time increased, an irrigation of $>0.1$ $\mathrm{m}^{3} / \mathrm{m}^{2}$ should be provided during the first year. Although A. sparsifolia has higher RGR compared to many other species, its root still requires a number of years to reach a deeper groundwater table. Thus, irrigation management is still necessary in later years. The frequency, time and amount of irrigation should depend more on the variations in SWC, and more water should be provided when gravimetric $\mathrm{SWC}<8 \%$ or soil matric potential is lower than plant water potential.

Thirdly, maintaining a stable groundwater table is also important. A tradeoff needs to be achieved between facilitating the establishment and maintenance of $A$. sparsifolia for stabilizing the environment surrounding the oases and minimizing the use of 
groundwater by the shrubs. Thus, the present expansion of oases should be controlled within a suitable range. Additional optimum irrigation management should be implemented in agriculture for decreasing groundwater exploitation. At present, flood irrigation is the major management practice that results in water wastage through evaporation.

Root growth occurs in the initial establishment stage and the whole lifetime of a genet. Once A. sparsifolia seedlings are established successfully in the oasis foreland, they spread vegetatively and form extensive clones with belowground tillers, and then can fulfill their multifunctionality. For the aim of oasis-desert ecotone protection and restoration, the ecological characteristics and management of A. sparsifolia require more attention.

\section{Acknowledgements}

The project was funded by the Knowledge Innovation Program of the Chinese Academy of Sciences (KZCX2-EW-316), the National Natural Science Foundation of China (41001171, 31070477, 30870471), the Western Light Foundation of the Chinese Academy of Sciences (XBBS201105), and the Key Program of Joint Funds of the National Natural Science Foundation of China and the Government of Xinjiang Uygur Autonomous Region of China (U1203201). We are grateful to the anonymous referees for their efforts in reviewing the manuscript.

\section{References}

Anyia A O, Herzog H. 2004. Water-use efficiency, leaf area and leaf gas exchange of cowpeas under midseason drought. European Journal of Agronomy, 20: 327-339.

Arredondo J T, Johnson D A. 2009. Root responses to short-lived pulses of soil nutrients and shoot defoliation in seedlings of three rangeland grasses. Rangeland Ecology Management, 62: 470-479.

Bruelheide H, Vonlanthen B, Jandt U, et al. 2010. Life on the edge-to which degree does phreatic water sustain vegetation in the periphery of the Taklamakan Desert? Applied Vegetation Science, 13: 56-71.

Buchanan-Wollaston V. 1997. The molecular biology of leaf senescence. Journal of Experimental Botany, 48: 181-199.

Cornelis W M, Ronsyn J, Meirvenne M V, et al. 2001. Evaluation of pedotransfer functions for predicting the soil moisture retention curve. Soil Science Society of America Journal, 65: 638-648.
Dias P C, Araujo W L, Moraes G A B K, et al. 2007. Morphological and physiological responses of two coffee progenies to soil water availability. Journal of Plant Physiology, 164: 1639-1647.

Gries D, Foetzki A, Arndt S K, et al. 2005. Production of perennial vegetation in an oasis-desert transition zone in NW China-allometric estimation, and assessment of flooding and use effects. Plant Ecology, 181: 23-43.

Gui D W, Lei J Q, Mu G J, et al. 2009. Effects of different management intensities on soil quality of farmland during oasis development in southern Tarim Basin, Xinjiang, China. International Journal of Sustainable Development \& World Ecology, 16: 295-301.

Gui D W, Lei J Q, Zeng F J, et al. 2010. Characterizing variations in soil particle size distribution in oasis farmlands-A case study of the Cele Oasis. Mathematical and Computer Modelling, 51: 1306-1311.

Guo H F, Zeng F J, Arndt S K, et al. 2008. Influence of floodwater irrigation on vegetation composition and vegetation regeneration in a Taklimakan desert oasis. Chinese Science Bulletin, 53: 156-163.

Hodge A. 2004. The plastic plant: root responses to heterogeneous supplies of nutrients. New Phytologist, 162: 9-24.

Jackson R B, Canadell J, Ehleringer J R, et al. 1996. A global analysis of root distribution for terrestrial biomes. Oecologia, 108: 389-411.

Li F, Bao W, Wu N, et al. 2008. Growth, biomass partitioning, and water-use efficiency of a leguminous shrub (Bauhinia faberi var. microphylla) in response to various water availabilities. New Forest, 36: 53-65.

Li X Y, Lin L S, Zhao Q, et al. 2010. Influence of groundwater depth on species composition and community structure in the transition zone of Cele oasis. Journal of Arid Land, 2: 235-242.

Liu B, Zeng F J, Guo H F, et al. 2009. Effects of groundwater table on growth characteristics of Alhagi sparisifoliz Shap. seedlings. Chinese Journal of Ecology, 28: 237-242.

Ma Y, Fan S, Zhou L, et al. 2007. The temporal change of driving factors during the course of land desertification in arid region of North China: the case of Minqin county. Environmental Geology, 51: 999-1008.

Maestre F T, Reynolds J F. 2007. Amount or pattern? Grassland responses to the heterogeneity and availability of two key resources. Ecology, 88: 501-511.

Maggio A, de Pascale S, Ruggiero C, et al. 2005. Physiological response of field-grown cabbage to salinity and drought stress. European Journal of Agronomy, 23: 57-67.

Mao W, Zhang T H, Li Y L, et al. 2012. Allometric response of perennial Pennisetum centrasiaticum Tzvel to nutrient and water limitation in the Horqin Sand Land of China. Journal of Arid Land, 4: 161-170.

Nicotra A B, Babicka N, Westoby M. 2002. Seedling root anatomy and morphology: an examination of ecological differentiation with rainfall using phylogenetically independent contrasts. Oecologia, 130: 136-145.

Padilla F M, Pugnaire F I. 2007. Rooting depth and soil moisture control Mediterranean woody seedling survival during drought. Functional 
Ecology, 21: 489-495.

Padilla F M, Miranda J D, Pugnaire F I. 2007. Early root growth plasticity in seedlings of three Mediterranean woody species. Plant and Soil, 296: 103-113.

Padilla F M, Miranda J D, Jorquera M J, et al. 2009. Variability in amount and frequency of water supply affects roots but not growth of arid shrubs. Plant Ecology, 204: 261-270.

Ryster P. 2006. The mysterious root length. Plant and Soil, 286: 1-6.

Sala O E, Lauenroth W K. 1982. Small rainfall events: an ecological role in semiarid regions. Oecologia, 53: 301-304.

Schenk H J, Jackson R B. 2005. Mapping the global distribution of deep roots in relation to climate and soil characteristics. Geoderma, 126: $129-140$.

Seyfried M S, Schwinning S, Walvoord M A, et al. 2005. Ecohydrological control of deep drainage in arid and semiarid regions. Ecology, 86: 277-287.

Siebert S, Gries D, Zhang X, et al. 2004. Non-destructive dry matter estimation of Alhagi sparsifolia vegetation in a desert oasis of Northwest China. Journal of Vegetation Science, 15: 365-372.

Thomas F M, Arndt S K, Bruelheide H, et al. 2000. Ecological basis for a sustainable management of the indigenous vegetation in a central-asian desert: presentation and first results. Journal of Applied Botany, 74: 212-219.

Thomas F M, Foetzki A, Arndt S K, et al. 2006. Water use by perennial plants in the transition zone between river oasis and desert in NW China. Basic and Applied Ecology, 7: 253-267.

Thomas F M, Foetzki A, Gries D, et al. 2008. Regulation of the water status in three co-occurring phreatophytes at the southern fringe of the Taklamakan Desert. Journal of Plant Ecology, 1: 227-235.

Villagra P E, Cavagnaro J B. 2006. Water stress effects on the seedling growth of Prosopis argentina and Prosopis alpataco. Journal of Arid
Environments, 64: 390-400.

Vonlanthen B, Zhang X, Bruelheide H. 2010. On the run for water-root growth of two phreatophytes in the Taklamakan Desert. Journal of Arid Environments, 74: 1604-1615.

Vonlanthen B, Zhang X, Bruelheide H. 2011. Establishment and early survival of five phreatophytes of the Taklamakan Desert. Flora, 206: 100-106.

Waisel Y, Eshel A, Kafkafi U. 1996. Plant Roots-The Hidden Half. New York: Marcel Dekker, Inc.

Xu B C, Deng X P, Zhang S Q, et al. 2010. Seedling biomass partition and water use efficiency of switchgrass and milkvetch in monocultures and mixtures in response to various water availabilities. Environmental Management, 46: 599-609.

Yin C Y, Duan B L, Wang X, et al. 2004. Morphological and physiological responses of two contrasting poplar species to drought stress and exogenous abscisic acid application. Plant Science, 167: 1091-1097.

Zeng F J, Bleby T M, Landman P A, et al. 2006. Water and nutrient dynamics in surface roots and soils are not modified by short-term flooding of phreatophytic plants in a hyperarid desert. Plant and Soil, 279: 129-139.

Zeng F J, Guo H F, Liu B, et al. 2009. Response of ecological properties of roots of Alhagi sparsifolia shap. seedlings to different irrigation treatments. Arid Zone Research, 26: 852-858.

Zeng F J, Lu Y, Guo H F, et al. 2012. Ecological characteristics of Alhagi sparsifolia Shap. seedling roots under different irrigation treatments. Russian Journal of Ecology, 43: 196-203.

Zhang K, Tian C Y, Li C J. 2012. Root growth and spatio-temporal distribution of three common annual halophytes in a saline desert, northern Xinjiang. Journal of Arid Land, 4: 330-341. 